\title{
Um nexo causal entre variáveis da violência em jovens
}

\section{A causal link among variables of violence in young people}

\author{
Nilton Soares Formiga ${ }^{1}$ \\ Catarina Isabel Fernandes Sintra ${ }^{2}$
}

\section{RESUMO}

Mesmo que a violência não seja um problema novo no mundo, a cada dia observase a luta da ciência para compreender e inibir esse fenômeno entre os jovens. Esta pode ser compreendida como qualquer ato físico ou moral contra seres humanos ou outros seres - com intenção de causar dano social ou psicológico, dor ou sofrimento, apontando em direção de inúmeros componente formadores da violência. Acontecimentos sociais e estudos brasileiros sobre o tema destacam-se a presença de componentes que se caracterizam a violência: condutas antissociais e delitivas, comportamentos agressivos e uso potencial de drogas. 284 estudantes da cidade de João Pessoa-PB, do sexo masculino e do sexo feminino, de 14 e 20 anos responderam o questionário de Comportamento agressivo, escala de condutas desviantes e uso potencial de drogas; como esperado, observou-se a associação entre as variáveis, as quais, formadoras do conceito da violência juvenil.

Palavras-chave: Conduta violenta. Modelo teórico. Jovens.

\section{ABSTRACT}

Even if violence is not a new problem in the world, each day there is the struggle of science to understand and to inhibit this phenomenon among young people. This can be understood as any physical or moral act against human beings - or other beings with intent to cause social or psychological damage, pain or suffering, pointing in the direction of many component makers of the violence. Social events and Brazilian studies on this theme emphasize the presence of components that characterize the violence, antisocial and criminal behavior, aggressive behavior and potential use of drugs. 284 students from João Pessoa, male and female, between 14 and 20 years old answered the questionnaire about aggressive behavior, deviant behavior scale and potential use of drugs; as expected, there was an association between variables, which, forming the concept of youth violence.

Keywords: Violent conduct. Theoretical model. Young people.

\footnotetext{
${ }^{1}$ Mestre em psicologia social pela universidade Federal da Paraíba; atualmente é doutorando na mesma universidade.nsformiga@yahoo.com

${ }^{2}$ Licenciada em Psicologia Criminal e do Comportamento Desviante pela Universidade Lusófona de Humanidades e Tecnologias de Lisboa; atualmente é doutoranda na mesma universidade. kathy sintra@hotmail.com
}

Esta obra foi licenciada com uma Licença Creative Commons - Atribuição 3.0 Não Adaptada. 


\section{INTRODUÇÃO}

Os acontecimentos violentos entre os jovens no Brasil tem sido mais um dos problemas que a sociedade vem enfrentando e buscado controlar. Esse não é tema novo e exclusivo, quanto ao investimento teórico, empírico da ciência humana, social ou da saúde, bem como, da promoção de práticas sociais e políticas em relação aos caminhos que aponte para uma solução desse problema juvenil. Desta forma, compreender e identificar as variáveis que, tanto em termos conceituais quanto de pesquisas, incluam-se no fenômeno da violência entre os jovens, tem sido importante para promover uma agente de proteção em relação a um fenômeno tão grave na contemporaneidade (ARENDT, 2009; MICHENER; DELAMATER; MYERS, 2005; PEQUENO, 2002; SANTOS; KASSOUF, 2008; ZALUAR, 2001).

Encontra-se na literatura atual uma quantidade de variáveis que compõem a explicação da violência, seja por motivos banais ou de barbárie (SANMARTíN, 2006). Mas, não se demora muito para que aperceba e identifique, na conduta cotidiana das cidades ou divulgação na mídia em geral, componentes que deflagram a violência juvenil, por exemplo: a agressão, a conduta desviante e o uso de droga licita ou ilícita. Acredita-se assim, que tais componentes estejam associados, de forma positiva entre si.

Sabe-se que o problema e a definição sobre a violência é uma questão fluida, porém, há um consenso entre os especialistas das ciências humanas, sociais, criminal, etc. que, apesar de sua polissemia e dinâmica multifacetada em relação à manifestação deste fenômeno na sociedade contemporânea, compreende-se que a violência trata-se de uma ação ou efeito de se empregar força física com um grau de dor ou sofrimento psicológico e social evitável ou intimidação moral, violação de direitos humanos contra alguém ou algo, destacando que esta violência é concreta, visível, está aumentando e não é exclusividade de jovens de classe baixa, com escassez sócio-econômica e educacional (OPAS, 2003; OUTHWAITE; BOTTOMORE, 1999; OPAS, 2003; SANMARTIN, 2006; WAISELFISZ, 2008).

Apesar de considerar que o aumento da violência entre os jovens, principalmente, entre aqueles sem história de delinqüência na época atual, deve-se a uma mudança cultural que, se perfila nos países ocidentais que estariam associados a um espírito individualista; esta mudança levaria a priorização de 
necessidades pessoais em que a meta seria a obtenção de prestígio e que, para mantê-lo, quando na falta de recursos ou mesmo de apoio social para sua realização, muitas vezes, seria alcançado através da conduta violenta (FORMIGA; MOTA, 2009). Não se tem encontrado no Brasil trabalhos empíricos, com base na modelagem estrutural, que comprove a interdependência entre as variáveis sinônimas ou preditoras do construto da violência.

Afinal, nas ciências que lidam com as variantes relacionais desse fenômeno, acredita-se numa inter-relação entre uma delinqüência e criminalidade. Não se trata mais, em suas variáveis estruturais e funcionalistas, de uma síndrome de rancor e revolta à ofensa sofrida, ao fracasso do sistema econômico e sócio-político ou a intensidade do abuso físico sofrido (da punição) experimentado pelo sujeito reivindicador. Pois, mesmo que tais reivindicações estejam sob um grito de justiça, todas essas justificativas decorre para o rompimento das normas socialmente aceitas destinadas a harmonia, respeito social e humano por parte do sujeito violento exigindo seu estado de direito particular, o qual, neste contexto, trata-se da quebra das normas sociais a fim de estabelecer um Estado de direito (CARDIA; SCHIFFER, 2002; ELZO, 1999; MINAYO et. all., 1999; PARKER; AUERHAHN, 1998; VELHO, 1985; VELHO, 2000).

A violência vai se tornando obscura na base humana da sociedade contemporânea, dissolvendo seu significado "positivo", o qual vinha carregado de um raciocínio de justiça e cumprimento dos direitos humanos, isto é: a violência, geralmente, vinda das classes baixas, especificamente a operária, deveria, em sua ação violenta, responder, a violência vinda da classe alta, com fins de controlar ou prevenir à violência surgida da classe baixa (MARTUCCELLI, 1999). Atualmente, tal problema não pode ser mais atribuído a essas condições, pois é possível acompanhar uma quantidade de fatos violentos em jovens de classe alta, com educação exemplar e organização familiar tradicional, que não representam nenhuma reivindicação social para o uso de forças. Assim, a violência vai compondo-se a partir de formas, tipos e modalidades, os quais, incluso no fenômeno da criminalidade e configurado, especificamente, como violação da lei e da norma social, (por exemplo, assassinato, seqüestro, roubo, destruição de patrimônio, etc.), mesmo que se vislumbre, com essas ações, a busca de um mundo justo e reivindicações sociais e políticas (ELZO, 1999; MISSE, 1993; PINO, 2007). 
Ao atribuir um sentido de causalidade ao problema da violência juvenil foi tomando como base de orientação a essa atribuição as concepções no direito penal no que se refere à cadeia de um desenvolvimento lógico entre delito e responsabilidade pessoal do autor da conduta ilícita e do dano. Concretamente, decorrente direto da conduta ilícita praticada pelo indivíduo a conseqüência é única e exclusiva dessa conduta, excluso, o estado de sobrevivência, a violência é em si, racional, e tem um foco psicossocial (MARZAGÃO, 2004; NORONHA, 2000; NUCCI, 2000). Assim, a violência é qualquer ato danoso incluindo, diretamente, os comportamentos agressivos, a conduta desviante (antissocial e delitivo) e a drogadição (por exemplo, uso potencial de drogas lícitas e ilícitas) (BROOK, J. S. et. all., 1997; FORMIGA, 2009; FORMIGA, 2010; ZHANG; WIECZOREK; WELTE, 1997).

Não se trata, apenas, de compreender esse fenômeno psicologicamente, pois, não é possível atribuí-la, exclusivamente, a uma condição patológica (BORDIN; OFFORD, 2000; COLLINS, 2009; DMS IV, AMERICAN PSYCHIATRIC ASSOCIATION, 2010; PENNEY; MORETTI, 2007). Apesar de resultados consistentes que apontam para essa perspectiva teórica mostrando caminhos para o espaço clínico no trabalho com jovens violentos, atualmente, a violência tem sido uma questão de saúde pública (OLIVEIRA, 2008). Tornou-se algo epidêmico, sejam os jovens que apresentem características sociais, econômicas e escolares baixas ou aqueles com uma estrutura social, familiar e escolar mais alta, ambos, têm apresentado semelhantes comportamentos violentos.

Desta maneira, questiona-se quanto à possibilidade de que o uso potencial de drogas possa influenciar um comportamento agressivo e uma conduta desviante (antissocial e delitiva). Sabe-se que a relação existente entre essas variáveis não é uma causalidade simples, mas, ao conhecê-la aponta-se em direção para a estruturação da suposta predição da violência e da criminalidade entre os jovens. Alguns estudos enfatizam as variáveis aqui abordadas apenas em termos de uma lineariedade, contemplando o fenômeno da violência de forma isolada ou bidirecionalidade entre estas variáveis. Por exemplo, em termos empíricos, estudos em países da Europa, Oriente, Oceania, America do Norte e America Latina, nos últimos dez anos, tem revelado uma interdependência entre violência e delinqüência, especificamente, em direção da relação do binômio uso de drogas-delinqüência, uso 
de drogas-violência e uso de drogas-criminalidade (FRÍAS et. all., 2000; GARCIA; JUNIOR, 2008; ILLESCAS; PUEYO, 2007).

Partindo dos pressupostos teóricos e metodológicos abordados no presente estudo, a fim de garantir uma robustez explicativa entre as variáveis, bem como, apontar em direção da dinâmica multivariada entre elas, pretende-se, a partir da análise e modelagem de equação estrutural no programa AMOS 7.0, verificar a seguinte hipótese: (1) o uso potencial de drogas associar-se-á ao comportamento agressivo e a conduta desviante, bem como estes últimos também estarão associados, estabelecendo assim, uma leitura psicossocial da violência.

A técnica da análise da Modelagem de Equação Estrutural (MEE) tem uma clara vantagem de levar em conta a teoria para definir os itens pertencentes a cada fator, bem como, apresentar indicadores de ajuste que permitam decidir objetivamente sobre a validade de construto da medida analisada e sua direção associativa entre as inúmeras variáveis. Desta forma, dois resultados principais podem ser esperados ao trabalhar com essa análise: 1- estimativa da magnitude dos efeitos estabelecida entre variáveis, as quais estão condicionadas ao fato de o modelo especificado (isto é, o diagrama) estar correto, e 2 - testagem do modelo em termos de consistência com os dados observados, a partir dos indicadores estatísticos, podendo dizer que resultado, modelo e dados são plausíveis, embora não se possa afirmar que sejam corretos (FARIAS; SANTOS, 2000). Atende-se assim, não a certeza total do modelo, mas, a sua probabilidade sistemática na relação entre as variáveis.

Um dos principais objetivos das técnicas multivariadas - neste caso, a Modelagem de Equação Estrutural - é expandir a habilidade exploratória do pesquisador e a eficiência estatística e teórica no momento em que se quer testar a hipótese levantada no estudo. Apesar das técnicas estatísticas tradicionais compartilharem de limitações, nas quais, é possível examinar somente uma relação entre as variáveis, é de suma importância para o pesquisador o fato de ter relações simultâneas; afinal, em alguns modelos existem variáveis que são independentes em algumas relações e, dependentes em outras. A fim de suprir esta necessidade, a Modelagem de Equação Estrutural examina uma série de relações de dependência simultâneas, esse método é particularmente útil quando uma variável dependente se torna independente em relações subseqüentes com as demais variáveis do estudo (HAIR et. al., 2005; SILVA, 2006). 
De acordo com Farias e Santos (2000), Hair et. al. (2005) e Zamora e Lemus (2008) a modelagem estrutural de um modelo - isto é, a análise de caminhos (path analysis) - relaciona-se as medidas de cada variável conceitual como confiáveis, acreditando que não existe erro de medida (mensuração) ou de especificação (operacionalização) das variáveis; cada medida é vista como exata manifestação da variável teórica. Desenha-se o modelo teórico que se pretende com base na relação hipotética entre as variáveis independente e dependente. Considerando que cada uma das figuras (variáveis) estará associada, busca-se provar a múltipla influência. Para obtenção desses resultados considera que os índices de ajuste (escores covariantes) - destacados na metodologia do presente estudo - enfatiza-se, simultaneamente, a teoria a que se propõem e a explicação entre as variáveis independentes e dependentes, além de garantir uma melhor avaliação associativa entre as variáveis do modelo. Com isso, o presente trabalho, ao abordar a modelagem estrutural, visa contribuir para a segurança dos resultados multivariados, bem como, corroborar ou propor novos estudos sobre o fenômeno da violência.

\section{MÉTODO}

\section{Amostra}

284 jovens, distribuídos igualmente no nível escolar fundamental e médio da rede privada e pública de educação na cidade de João Pessoa - PB, com idades entre 14 e 20 anos e uma renda econômica media de 1.160,00 Reais. Os respondentes foram do sexo masculino e do sexo feminino, predominando a participação dos homens (62\%); essa amostra foi não probabilística e sim intencional, o propósito era garantir a validade interna dos resultados da pesquisa. 


\section{Instrumento}

Os participantes responderam um questionário composto das seguintes medidas:

O POSIT - The Problem Oriented Screening Instrument for Teenagers. Validado para o contexto brasileiro por Coelho Junior, Gontiès e Gouveia (2003), trata-se de uma medida correspondente a 81 itens distribuídos em sete fatores os quais avaliam a potencialidade do futuro consumo de bebidas alcoólicas e outras drogas em jovens (Por exemplo, seus amigos se aborrecem nas festas onde não servem bebidas alcoólicas; você fez dano a si mesmo ou causou dano a alguém sob o efeito de drogas?; costuma perder atividades ou acontecimentos porque gastou dinheiro com drogas ou bebidas alcoólicas?; sentiu alguma vez que era dependente ao álcool ou das drogas?; seus amigos levam drogas, lícitas ou ilícitas às festas? etc.). Os respondentes deveriam indicar numa escala de resposta de forçada (sim ou não) quanto ao o uso e abuso de substância lícitas e elícitas. Os autores da escala encontraram sete fatores de primeira ordem, os quais explicaram conjuntamente $27,7 \%$ da variância total e seus índices de consistência interna (Alfas de Cronbach) variaram de 0,65 a 0,80 .

Escala de Condutas Antisociais e Delitivas. Este instrumento, proposto por Seisdedos (1988) e validado por Formiga e Gouveia (2003) para o contexto brasileiro, compreende uma medida comportamental em relação às Condutas AntiSociais e Delitivas. Tal medida é composta por quarenta elementos, distribuídos em dois fatores, como segue: o primeiro envolve as condutas antisociais, em que seus elementos não expressam delitos, mas comportamentos que desafiam a ordem social e infringem normas sociais (por exemplo, jogar lixo no chão mesmo quando há perto um cesto de lixo; tocar a campainha na casa de alguém e sair correndo). $O$ segundo fator relaciona-se às condutas delitivas. Estas incorporam comportamentos delitivos que estão fora da lei, caracterizando uma infração ou uma conduta faltosa e prejudicial a alguém ou mesmo à sociedade como um todo (por exemplo, roubar objetos dos carros; conseguir dinheiro ameaçando pessoas mais fracas). Para cada elemento, os participantes deveriam indicar o quanto apresentava o comportamento assinalado no seu dia-a-dia. Para isso, utilizavam uma escala de resposta com dez

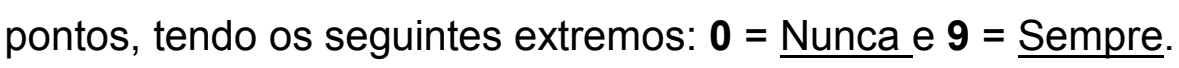


A presente escala revelou indicadores psicométricos consistentes identificando os fatores destacados acima; para a Conduta Antisocial encontrou-se um Alpha de Cronbach de 0,86 e a Conduta Delitiva ou Delinqüente, 0,92. Considerando a Análise Fatorial Confirmatória, realizada com o Lisrel 8.0, comprovou-se essas dimensões previamente encontradas $\left(\chi^{2} / g I=1,35 ; \mathrm{AGFI}=0,89\right.$; PHI $(\phi)=0,79, p>0,05)$ na análise dos principais componentes (FORMIGA; GOUVEIA, 2003). Neste estudo, essa escala apresentou alfas próximos aos encontrados nos estudo de Formiga (2003) e por Formiga e Gouveia (2003), tanto para Conduta Antisocial (alpha de Cronbach, $\alpha=0,84$ ) e para Conduta Delitiva ou Delinqüente, $\alpha=0,90$ mantendo sua consistência interna.

Questionário do comportamento agressivo. Este instrumento, composto por 26 itens, distribuídos em quatro fatores: agressão física (por exemplo, "Se alguém me bater, eu bato de volta"), agressão verbal (por exemplo, "eu não consigo ficar calado (a) quando as pessoas discordam de mim") raiva (por exemplo, "algumas vezes me sinto como uma bomba preste a explodir") e hostilidade (por exemplo, "eu desconfio de pessoas estranhas que são amigáveis demais") foi proposto por Buss e Perry (1999), o mesmo foi validado em uma população de infratores por Williams et. all. (1996), encontrando uma estrutura composta por 26 itens distribuídos como agressão física, agressão verbal, raiva, hostilidade. Formiga e cols. (2005) e Formiga et. all. (2006), no Brasil, aplicaram essa escala como estudo exploratório numa amostra de jovens não delinqüentes, identificando, apenas dois fatores, diferentes das destacadas por Buss e Perry (1999); a partir de uma analise exploratória e analise fatorial confirmatória identificaram os fatores de agressão física e descompensação emocional, os quais se relacionavam positivamente.

No presente estudo, realizou-se uma análise fatorial confirmatória (AFC) e de modelagem de equação estrutural (MEE) para este instrumento; este revelou indicadores de ajustes recomendados na literatura vigente (BYRNE, 1989; HAIR et. all.; VAN DE VIJVER; LEUNG, 1997): $x^{2} / g I=0,97 ; \mathrm{GFI}=0,96$ e AGFI = 0,93; CFI = 1,00; RMSEA $(90 \% \mathrm{IC})=0,00$ (0,00-0,03), $\mathrm{CAIC}=851,70$ e $\mathrm{ECVI}=1,19$, apresentando garantia de sua confiabilidade fatorial e evidência empírica para aplicação e mensuração no contexto paraibano; esses resultados diferenciam dos encontrados por Buss e Perry (1999), pois, não somente a etiquetagem dos fatores estabeleceu-se como agressão física e descompensação emocional, bem como, a quantidade de itens conglomerados em seus fatores foram menores.

Cad. de Pesq. Interdisc. em Ci-s. Hum-s., Florianópolis, v.12, n.100, p.86-104, jan/jul 2011 
Assim, utilizou-se a adaptação dessa versão no presente estudo, na qual os itens eram respondidos numa escala de resposta do tipo Likert com os extremos variando de $\mathbf{1}=$ Discordo Totalmente a $\mathbf{5}=$ Concordo Totalmente.

Caracterização Sócio-Demográfica. Foram elaboradas perguntas que contribuíram para caracterizar os participantes deste estudo (por exemplo, sexo, idade, classe sócio-econômica), bem como, realizar um controle estatístico de algum atributo que possa interferir diretamente nos seus resultados.

\section{Procedimento}

Procurou-se definir um procedimento padrão que consistia em aplicar os instrumentos coletivamente em sala de aula, em escolas em diversas áreas urbanas da cidade de João Pessoa - PB. Desta forma, colaboradores com experiência metodológica e ética, ficaram responsáveis pela coleta dos dados. Após conseguir a autorização tanto da diretoria da escola quanto dos professores responsáveis pela disciplina, os aplicadores se apresentavam em sala de aula como interessados em conhecer as opiniões e os comportamentos das pessoas no cotidiano, solicitando a colaboração voluntária dos estudantes no sentido de responderem um questionário breve.

Foi-lhes dito que não havia resposta certa ou errada e que, mesmo necessitando de uma resposta individual, estes não deveriam sentir-se obrigados em responder o instrumento podendo desistir a qual momento, seja quanto tivesse o instrumento em suas mãos ou ao iniciar sua leitura, ou outra eventual condição, bastava apenas contatar as pessoas responsáveis pela aplicação do instrumento no local. A todos era assegurado o anonimato das suas respostas, enfatizando que elas seriam tratadas, estatisticamente, em seu conjunto de respostas; apesar do questionário ser auto-aplicável, contando com as instruções necessárias para que possam ser respondidos, os colaboradores estiveram presentes durante toda a aplicação para retirar eventuais dúvidas ou realizar esclarecimentos que se fizessem indispensáveis, não interferindo na lógica e compreensão das respostas dos respondentes. 30 minutos foram suficientes para concluir essa atividade.

Em relação à análise dos dados da pesquisa, utilizou-se a versão 15.0 do pacote estatístico SPSS para Windows e computadas estatísticas descritivas (tendência central e dispersão). No AMOS 7.0 computaram e avaliaram-se os 
indicadores estatísticos para o Modelo de Equações Estruturais (SEM) considerando, segundo uma bondade de ajuste subjetiva, os seguintes indicadores: $\chi^{2} / \mathrm{gl}$ (grau de liberdade), que admite como adequados, índices entre 2 e 3 , aceitando-se até 5; Raiz Quadrada Média Residual - $\underline{\mathrm{RMR}}$, indica o ajustamento do modelo teórico aos dados, na medida em que a diferença entre os dois se aproxima de zero (0); índices de qualidade de ajuste, dados pelos GFI/AGFI, que medem a variabilidade explicada pelo modelo, e com índices aceitáveis a partir de 0,80; $\underline{\mathrm{CFI}}$, que compara de forma geral o modelo estimado e o modelo nulo, considerando valores mais próximos de um (1) como indicadores de ajustamento satisfatório e o RMSEA, que refere-se ao erro médio aproximado da raiz quadrática, deve apresentar intervalo de confiança como ideal situado entre 0,05 e 0,08. (BYRNE, 1989; HAIR et. al., 2005; JORESKÖG; SÖRBOM, 1989).

\section{RESULTADOS E DISCUSSAO}

Neste estudo pretende-se testar um modelo teórico (causal) no qual variável como uso potencial de droga, conduta desviante e comportamento agressivo estejam associados entre si, considerando um modelo recursivo de equações estruturais e gerou-se, no AMOS GRAFICS 7.0, o modelo a que se propôs; este, apresentou saturação que explica o modelo em questão exposto na figura 1. Após as devidas modificações de ajuste do modelo adequado, observou-se a seguinte razão: $\chi^{2} / \mathrm{gl}=0,78, \mathrm{p}<0,69 ; \mathrm{RMR}=0,01 ; \mathrm{GFI}=0,99 ; \mathrm{AGFI}=0,96 ; \mathrm{CFI}=1,00 \mathrm{e}$ RMSEA $=0,01(0,00-0,05)$. Os pesos da variável uso potencial de drogas associouse $(\lambda=0,28)$ positivamente as condutas desviantes e o comportamento agressivo ( $\lambda$ $=0,14)$; estas ultimas variáveis - condutas desviantes e comportamento agressivo também, estiveram, positivamente, associadas $(\lambda=0,16)$ entre si, de acordo com o que se hipotetizava. Esses resultados podem ser representados na figura abaixo. 
Figura: Modelo teórico para explicação das variáveis da que compõem a violência juvenil.

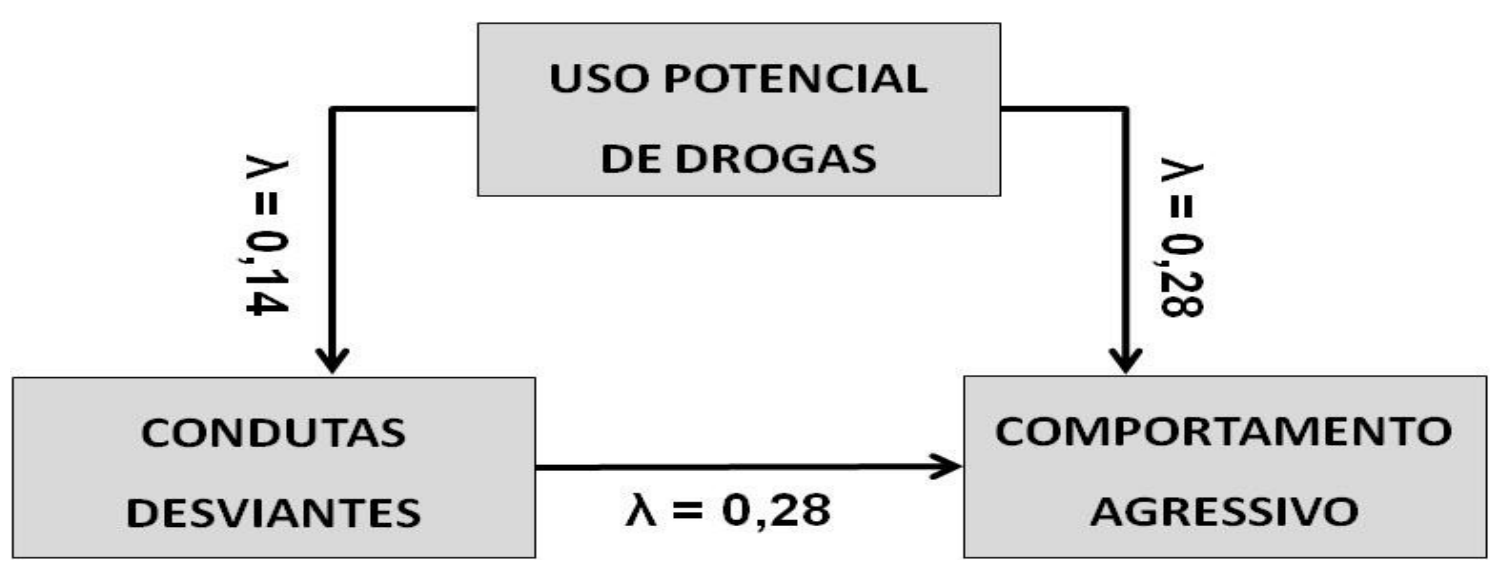

A associação entre essas variáveis, não somente é foco de interpretação da ciência humana e social, mas, também, representação discursiva entre os leigos: geralmente, aponta-se que a bebida alcoólica e a maconha como as substâncias psicotrópicas mais consumidas pelos jovens no Brasil (MOREIRA et. all, 2008). De acordo com Coelho Junior et all. (2003), o uso potencial de drogas diz respeito a uma medida que avalia problemas de consumo de drogas entre os jovens, compreendido como tendência ao consumo de drogas. Nessa compreensão, vê-se o quanto é importante o aspecto preventivo do consumo de drogas.

Não se trata apenas de uma saliência perceptiva na dinâmica cotidiana em relação à causalidade atributiva entre drogas e violência; empiricamente, a partir desses resultados, o uso potencial de drogas entre os jovens, provavelmente, poderá influenciar a conduta desviante e o comportamento agressivo, comprovando tanto o conceito apresentado pela OMS quanto as perspectivas interventivas exigidas nas demais instituições de controle social e apoio humanitário juvenil - por exemplo, a família, a escola, polícia, ONGs, etc. - sobre violência. Com os resultados desse estudo busca-se convergir para as reflexões de outros estudiosos (HEMPHILL; TOUMBOUROU; CATALANO, 2005; FERGUSON; MIGUEL; HARTLEY, 2009; SKARA et. al., 2008; YOUNG; SWEETING; WEST, 2008), os quais revelaram, também, a existência de uma influência recíproca, respectivamente, entre uso de álcool e drogas, conduta desviante e comportamento agressivo. Destaca-se com isso, a possibilidade de se avaliar um sistema teórico e empírico em direção de uma psiossociologia a violência juvenil. 
Este fenômeno, considerado de característica juvenil, não seria apenas relacionado ao jovem que apresentasse um dos construtos salientados no modelo apresentado, mas, aponta-se para uma dinâmica entre as variáveis destacadas: isto é, quanto maior a pontuação no uso potencial de drogas, maior seria a probabilidade de apresentar conduta antissocial e delitiva, bem como, comportamentos agressivos. Desta forma, o presente estudo pretende indicar um vetor em direção de caminhos teóricos e práticos na elaboração e implementação de políticas publicas contra a violência e programas sociais mais pontuais no combate ao consumo de drogas.

A existência dessa associação entre 0 uso potencial de drogascomportamento agressivo-conduta desviante, não pode ser considerando definitivo, alguns limites existem quanto a tal associação; mas, este estudo procura responder, parcimoniosamente, quanto ao problema da mensuração desse fenômeno, no que se refere aos indicadores empíricos; até porque, na literatura vigente, justificativas são apresentadas em relação a inconsistência entre tais variáveis e sua causalidade com o construto violência (FAGAN, 1993; MINAYO et. all., 1999; OSGOOD,1998).

Porém, ao comparar os resultados desse estudo aos achados científicos de Deslandes (1997; HEMPHILL; TOUMBOUROU; CATALANO, 2005; FERGUSON; MIGUEL; HARTLEY, 2009; YOUNG; SWEETING; WEST, 2008; SKARA et. all., 2008) que observaram associações entre tais variáveis; mas, o estudo de Deslandes (1997) reforça de forma enfática os resultados aqui destacados. Esse autor acompanhou os casos de violência atendidos em hospitais do Rio de Janeiro-Brasil e observou que dos mais de 2000 atendimentos por todas as causas externas (especificamente, agressões) em um período de maio a junho de 1996, em dois hospitais de pronto atendimento no Rio de Janeiro, aproximadamente, $26 \%$ dos casos estavam envolvidos com o uso de drogas; nestes casos mais de $80 \%$ tinha consumido álcool, associado a maconha e outras drogas.

Outro estudo que contribui para os resultados desse trabalho é que desenvolveu Moreira et. all. (2008); de acordo com esses autores, o consumo de álcool pelos jovens tem se associado a homicídios, suicídios, violência doméstica, crimes sexuais, acidentes de trânsito, tanto sendo a vítima ou perpetrador destas violências, como também, com a diminuição do rendimento escolar. Uma associação mais intensa entre esses variáveis se dá quando é maior à ingestão de álcool, pois de acordo com os autores, o álcool prejudica o julgamento e a habilidade de reconhecimento e compreensão dos riscos. Além dos adolescentes, expostos à 
violência, mostrarem altas taxas de consumo de tabaco, álcool, etc., estes ficam suscetíveis, também, ao uso de drogas ilícitas.

Apesar dos resultados apresentados responderem ao que se previa, alguns limites devem ser considerados, por exemplo: é merecedor de atenção nas associações entre as variáveis a precaução metodológica, principalmente, em relação a neutralidade da resposta dos sujeitos ao revelar o real uso de álcool ou outras substâncias psicoativas, pois, todo cuidado é necessário, quando tratar desse problema, por ele ser matéria de preconceito e desconfiança entre os respondentes consumidores de álcool e drogas.

Mesmo que tais resultados provem a relação entre as variáveis, como então prevenir? A sustentabilidade desses problemas entre os jovens é bem mais complexa do que, simplestemente, ter em mente o consumo ou não de álcool e drogas; nessas condições é importante os espaços institucionais que garantam maior controle do comportamento social - não se deve confundir como ditadura comportamental ou social - como a família, escola, comunidades sociais de bairros, etc.

O problema do uso de drogas é grave e muito mais perigoso é quando este problema influencia outros comportamentos, por exemplo, a agressão e a delituosidade entre os jovens. Os espaços de socialização juvenil vêm a cada dia contaminado pela possibilidade de que tudo é permitido e que regras não são prazerosas e que tem que curtir a vida ao máximo, condição fomentadora de conflito para as instituições de controle. Tem Gastado muito tempo procurando convencer se deve ou não ingerir álcool, porém, pouco em formação sobre as possíveis causas dessa atitude e sua associação a outros problemas de comportamento, a qual não somente é geradora de problemas de saúde física e psíquica quanto sociais. 


\section{REFERENCIAS}

ARENDT, H. Sobre a violência. Civilização brasileira: Rio de Janeiro, 2009.

BORDIN, I. A. S.; OFFORD, D. R. Transtorno de conduta e comportamento antisocial. Revista de Psiquiatria, v.22, p. 12-15, 2000.

BROOK, J. S. et. al. Drug Use and Delinquency: Shared and Unshared Risk Factors in African American and Puerto Rican Adolescents. The Journal of Genetic Psychology, v.158, n.1, p. 25-39, 1997.

BUSS, A. H.; PERRY, M. The aggression questionnaire. Journal of Personality and Social Psychology, v.63, n.3, p. 452-459, 1999.

BYRNE, B. M. A primer of LISREL: Basic applications and programming for confirmatory factor analytic models. New York: Springer-Verlag, 1989.

CÁRDIA, N.; SCHIFFER, S. Violência e desigualdade. Revista Ciência e Cultura, p. 25-31, 2002. Disponível em: <http://www.nevusp.org/downloads/down070.pdf> Acesso em: 25 Jul 2008.

CLARK, D. B.; VANYUKOV M. M.; CORNELIUS J. Childhood Antisocial Behavior and Adolescent Alcohol Use Disorders. Alcohol Research and Health, v.26, n.2, p.109-15, 2002.

COELHO JUNIOR, L. L.; GONTIĖS, B.; GOUVEIA, V. V. Questionário para detectar potencial uso de drogas entre adolescentes (Posit): Adaptação brasileira. Jornal Brasileiro de Psiquiatria, v.52, n.2, p. 109-116, 2003.

COLLINS, R. Micro and Macro Causes of Violence. International Journal of Conflict and Violence, v.3, n.1, p. 9-22, 2009.

DESLANDES, S. F. Relatório Final da Pesquisa "O Impacto da Violência nos Serviços de Emergência Hospitalar. Rio de Janeiro: Centro Latino-Americano de Estudos de Violência e Saúde Jorge Careli, Departamento de Epidemiologia e Métodos Quantitativos em Saúde, Escola Nacional de Saúde Pública, Fundação Oswaldo Cruz, 1997. 
DSM-IV. Manual de desordem mentais. Diagnóstico e estatística. Porto Alegre: Artes Médicas, 2010.

ELZO, J. I. Materiales para estudio y prevención de la violencia juvenil. 1999.

Disponível em: <http://www.fad.es/sala lectura/CongresoViolencia.pdf>. Acesso em: 15 mar 2008.

FAGAN, J. Interactions among drugs, alcohol and violence. Health Affairs, v.12, n.4, p. 65-79, 1993.

FARIAS, S. A.; SANTOS, R. C. Modelagem de Equações Estruturais e Satisfação do Consumidor: uma Investigação Teórica e Prática. Revista de Administração

Contemporânea, v.4, n.3, p. 107-132, 2000.

FERGUSON, C. J.; SAN MIGUEL, C.; HARTLEY, R. D. A multivariate analysis of youth violence and aggression: The influence of family, peers, depression and media violence. Journal of Pediatrics, v.155, n.6, p. 904-908, 2009.

FORMIGA, N. S. Fidedignidade da escala de condutas anti-sociais e delitivas ao contexto brasileiro. Psicologia estudo, v.8, n.2, p. 133-138, 2003.

FORMIGA, N. S.; GOUVEIA, V. V. Adaptação e validação da escala de condutas anti-sociais e delitivas ao contexto brasileiro. Revista Psico, v.34, n.2, p. 367-388, 2003.

FORMIGA, N. S. Afiliação com pares sócio-normativos e condutas desviantes. Cadernos de Pesquisa Interdisciplinar em Ciências Humanas, v.10, p. 5-26, 2009.

FORMIGA, N. S. Valores humanos e condutas desviantes: Sua acurária correlacional em jovens brasileiros. Cadernos de Pesquisa Interdisciplinar em Ciências Humanas, v.11, p. 1-20, 2010.

FORMIGA, N. S.; MOTA, H. M. Estilo da orientação cultural e condutas desviantes: um estudo correlacional em jovens paraibanos. Cadernos de Pesquisa Interdisciplinar em Ciências Humanas, v.10, n.97, p. 158-180, 2009

FORMIGA, N. S. et al. A busca de sensação e as variações condutuais da violência juvenil: A experiência em correr. risco como explicação das condutas desviantes, comportamento agressivo e uso potencial de drogas. In: REUNIÃO ANUAL DA 
SBPC: SEMEANDO INTERDISCIPLINARIDADE, 58, 2006, Florianópolis. Anais... Florianópolis. 2006.

FORMIGA, N. S.; YEPES, C.; ALVES, I. Correlatos entre traços de personalidade e afiliação com pares sociais: Reflexões a respeito da formação personalística em jovens. In: CONGRESSO CIENTÍFICO DO CEULP-ULBRA: ÉTICA E CIÊNCIA, 4, 2005, Palmas. Anais... Palmas, 2005.

FRÍAS, M. A., et al. Predictores de la delincuencia juvenil. La Psicología Social en México, v.8, p .486-492, 2000.

GARCIA, K. S. L.; JUNIOR, M. L. C. Antisocial behavior and alcohol consumption by school adolescents. Revista latino-americana de enfermagem, v.16, n.2, p. 299305, 2008.

HAIR, J. F. et al. Análise Multivariada de Dados. Porto Alegre: Bookman. 2005.

HEMPHILL, S. A.; TOUMBOUROU, J. W.; CATALANO, R. F. Predictors of violence, antisocial behavior and relational aggression in Australian adolescents: A longitudinal study. Report for the criminology research council. 2005.

ILLESCA, S. R.; PUEYO, A. A. The psychology of criminal conduct. Papeles del psicológo, v.28, n.3, p 147-156, 2007.

JORESKÖG, K.; SÖRBOM, D. LISREL 7 user's reference guide. Mooresville: Scientific Software, 1989.

MARTUCCELLI, D. Reflexões sobre a violência na condição moderna. Tempo social, v.11, n.1, p. 157-175, 1999.

MARZAGÃO, G. H. B. Relação de causalidade no Direito Penal. Teorias da equivalência das condições, da causalidade adequada e da imputação objetiva sem mistérios. Jus Navigandi, v.8, n.395, 2004. Disponível em:

<http://jus2.uol.com.br/doutrina/texto.asp?id=5539>. Acesso em: 18 jul 2010.

MICHENER, H. A.; DELAMATER, J. D.; MYERS, D. J. Agressão. In: MICHENER, H. A.; DELAMATER, J. D.; MYERS, D. J (Org.), Psicologia Social. São Paulo: Thomson, 2005. p. 329-357. 
MINAYO, M. C. S. et all. Fala galera: Juventude, violência e cidadania na cidade o Rio de Janeiro. Rio de Janeiro: RJ. Garamond.1999.

MISSE, M. Crime e pobreza: velhos enfoques, novos problemas. Manuscrito apresentado no seminário: Brasil em perspectiva: os anos 90. 2002. Laboratório de pesquisa social. Departamento de ciências sociais do IFCS-UFRJ. Disponível em: < http://www.nevusp.org/downloads/down070.pdf> . Acesso em: 05 Ago 2008.

MOREIRA, T. C. et. al. A violência comunitária e o abuso de álcool entre adolescentes: Comparação entre sexos. Jornal de Pediatria, v.84, n.3, p. 244-250, 2008.

NORONHA, E. M. Direito Penal: introdução e parte geral. São Paulo: Saraiva, 2000.

NUCCI, G. S. Código Penal Comentado. São Paulo: RT, 2000.

OLIVEIRA, W. F. Violência e Saúde Coletiva: contribuições teóricas das ciências sociais à discussão sobre o desvio. Saúde e Sociedade, v.17, n.3, p.42-53, 2008.

OLMO. R. Violencia juvenile y consumo de drogas: Modelos teóricos (Algumas inquietudes preliminares). CONGRESSO VIRTUAL SOBRE VIOLENCIA JUVENIL Y CONSUMO DE DROGAS, 1999. Anais... Disponível em:

<http://www.fad.es/sala lectura/CongresoViolencia.pdf>. Acesso em: 15 mar 2008.

ORGANIZAÇÃO PANAMERICANA DE SAÚDE (OPAS). Informe mundial sobre la violencia y la salud. Whashinton: OPS/WHO, 2003.

OSGOOD, D. W. Drugs, Alcohol and Adolescent Violence. Center for the Study and Prevention of Violence. University of Colorado, 1999. Disponível em:

<www.colorado.edu/cspv> . Acesso em: 20 junho 2010.

OUTHWAITE, W.; BOTTOMORE, T. Dicionário do pensamento social do século XX. Rio de Janeiro: Jorge Zahar, 1999.

PARKER, R. N.; AUERHAHN, K. Alcohol, drugs and violence. American review sociology, v.24, p. 291-311, 1998. 
PENNEY, S. R.; MORETTI, M. M. The Relation of Psychopathy to Concurrent Aggression and Antisocial Behavior in High-Risk Adolescent Girls and Boys.

Behavioral Sciences and the Law, v.25, p.21-41, 2007.

PEQUENO, M. Violência e direitos humanos. In: LYRA, Rubens P. (Orgs.). Direitos humanos: Os desafios do século XXI. Uma abordagem interdisciplinar. Brasília: Brasília Jurídica, 2002. p. 121-133.

PINO, A. Violência, educação e sociedade: Um olhar sobre o Brasil contemporâneo. Educação \& sociedade, v.28, n.100, p. 763-785, 2007.

SANMARTÍN, J. Que es esa cosa llamada violencia? Boletín Diario de Campo, p. 11-29, 2006. Suplemento.

SANTOS, M. J.; KASSOUF, A. L. Estudos econômicos das causas da criminalidade no Brasil: Evidências e controvérsias. Revista de econômica, v.9, n. 2, p. 343-372, 2008.

SEISDEDOS, N. C. Cuestionario A - D de conductas antisociais delictivas. Madri: TEA, 1998.

SILVA, J. S. F. Modelagem de Equações Estruturais: Apresentação de uma metodologia. 2006. Dissertação (Mestrado em Engenharia de Produção). Universidade Federal do Rio Grande do Sul, Porto Alegre, 2006. Disponível em: $<$ http://hdl.handle.net/10183/8628>. Acesso em: 25 ago 2009.

SKARA S. et al. Physical and relational aggression as predictors of drug use: gender differences among high school students. Addictive behaviors, v.33, n.12, p.15071515, 2008.

VAN DE VIJVER, F.; LEUNG, K. Methods and data analysis for cross-cultural research. Thousand Oaks, CA: Sage Publications, 1997.

VELHO, G. Desvio e divergência: Uma crítica da patologia social. Rio de Janeiro: Jorge Zahar, 1985.

VELHO, G. Violência, reciprocidade e desigualdade: Uma perspectiva antropológica. In: VELHO, G; ALVITO, M. (Orgs.). Cidadania. Rio de Janeiro: Editora UFRJ/ Editora FGV, 2000. 
WAISELFISZ, J. Mapa da violência dos municípios brasileiros. Brasília: OEI, 2008.

WILLIAMS, T. Y. et. all. Factor structure and convergent validity of the aggression questionnaire in an offender population. Psychological Assessment, v.8, n.4, p. 398-403, 1996.

YOUNG, R.; SWEETING, H.; WEST, P. A longitudinal study of alcohol use and antisocial behaviour in young people. Alcohol and Alcoholism, v.43, p. 204-14, 2007.

ZALUAR, A. Violence in Rio de Janeiro: Styles of leisure, drug use and trafficking. International Social Science Journal, v.53, n.169, p. 369-378, 2001.

ZAMORA, C. S.; LEMUS, I. S. Modelos de Ecuaciones Estructurales: ¿Qué es eso? Ciencia \& Trabajo, v.10, n.29, p. 106-110, 2008.

ZHANG, L.; WIECZOREK, W. F.; WELTE, J.W. (1997). The nexus between alcohol and violent crime. Alcoholism: Clinical and Experimental Research, v.21, p. 12641271.

Artigo:

Recebido em: 03/01/2011

Aceito em: 18/07/2011 